\title{
Editorial
}

\section{SOBRE A \\ INTERDISCIPLINARIDADE DA CIÊNCIA DA INFORMAÇÃO}

"Since everything is connected with everything somehow information science would have evelop some kind of conceptual navigation system (...). This is the difference between the information scientist and the weaving bird: The latter already has its plans provided by evolution. In our case the next step of evolution in science waits to be done, by whomever."

(WERSIG, 1993, p.239)

Como assinalou Saracevic (1991), por ocasião do evento comemorativo dos 20 anos do Departamento de Estudos da Informação da Universidade de Tampère, na Finlândia, o estudo dos problemas da informação, no âmbito dos fenômenos da comunicação humana, não podem ser resolvidos dentro de uma única área da atividade científica. Torna-se necessário, desse ponto de vista, o desenvolvimento de abordagens que favoreçam a interdisciplinaridade, ou seja, que permitam o relacionamento teórico da ciência da informação com outras áreas da ciência. Para o autor, "a característica interdisciplinar da ciência da informação não precisa ser procurada, está lá, no âmago do próprio campo científico" (SARACEVIC, 1995).

Nesse contexto, caberia à Ciência da Informação buscar, na interdisciplinaridade, sua estratégia de atuação e, nesse sentido, Wersig - também presente no evento de Tampère - propõe que se adote uma estratégia que envolva a interação com conceitos e modelos de outras áreas, de modo a construir um quadro referencial teórico que possa trabalhar as formas de expressão do conhecimento científico como estruturas que transformam e são transformadas no processo de produção e comunicação social (WERSIG, 1993).

Mas, em que consiste a "interdisciplinaridade" no campo científico? Em sua Memória Científica Original, publicada no presente número de Inf.\&Soc.: Est., Pinheiro adota a definição de Japiassu (1976, p.22), que entende a interdisciplinaridade como incorporação dos "resultados de várias disciplinas, tomando-lhes de empréstimo esquemas conceituais de análise, a fim de fazêlos integrar depois de havê-los comparado e julgado".

Quase 20 depois dessa proposição, Wersig (1993, p.238) "desenharia" essa ideia, na sua proposta de "rede de projetos" como modus operandi mais produtivo para o trabalho de abordagem científica da informação: nesse modelo, os conceitos fundamentais "se constituem semelhantemente a ímãs, ou "atratores", atraindo os materiais [teóricos ou empíricos] para fora [dos seus respectivos campos] e reestruturando-os dentro da estrutura científica da informação". As mandalas de Pinheiro mostram essa rede ao longo de 23 anos.

Nesse sentido, podemos até mesmo reivindicar, para a Ciência da Informação, abordagens multi ou trans disciplinares, mas será necessário, sempre, ter em mente o que diz Japiassu (1976) sobre ambas: a primeira invocaria justaposição em determinado trabalho, demandando recursos de várias disciplinas científicas, sem, contudo, enriquecer as disciplinas envolvidas na abordagem; a segunda representaria, ainda, um sonho acadêmico, que poderá, ou não, se traduzir numa nova cultura acadêmica.

Por fim, sobre a <interdisciplinaridade>, discutida por inúmeros autores da área da Ciência da Informação, como mostra uma busca na Base de Dados da Ciência da Informação ${ }^{1}$

\footnotetext{
Foram recuperados 214 textos, publicados em periódicos científicos e apresentados em eventos, sendo o mais recente datado de 2018 e o mais antigo datado de 1981 .
} 
e a leitura do artigo de Pinheiro, é suficiente lembrar as palavras de Wersig em Tampère: se a evolução já providenciou, ao pássaro-tecelão, condições para construir intricados ninhos sem outros atributos além da biologia, a Ciência da Informação exige que o próximo passo da "evolução", na epistemologia e teoria, seja dado pelos cientistas, no dia-a-dia de suas pesquisas. Por todos, e por cada um de nós, que compomos este campo científico.

Gustavo Henrique de Araújo Freire Isa Maria Freire Editores

\section{REFERÊNCIAS}

PINHEIRO, L.V.R. Mutações na Ciência da Informação e reflexo nas mandalas interdisciplinares. Inf.\&Soc.: Est., v.28, n.3, 2018.

SARACEVIC, T. Interdisciplinary Nature of Information Science: Where it Came From and Where is it Going. In: Information 2000: An Interdisciplinary Future. A Conference for Students and Professionals in the Information Professions. 14-15 Jul., 1994. Proceedings... Denton: University of North Texas: 1994.

SARACEVIC, T. Information science: origin, evolution and relations. In: International Conference held for the celebration of 20th Anniversary of the Department of Information Studies, 26-28 Aug. Preprint. Tampère: University of Tampere, 1991.

WERSIG, G. Information science: The study of postmodern knowledge usage. Information Processing \& Management, v.29, n.2, p.229-239, 1993. 